health services to erode the human rights of individuals who fall liable to treatment under mental health legislation. Corporations that thrive financially from the forcible treatment of vulnerable individuals deserve more scrutiny. Unless the College can demonstrate the highest standards of integrity in this sensitive area, it will rightly lose its influence in our democratic institutions and squander the high regard in which it is held by the public. I feel sure that all members of the College would share my concerns.

Fareed Bashir Bolton, Salford and Trafford Mental Health Trust, Edenfield Centre, Prestwich Hospital, Bury New Road, Manchester M25 3BL, email: fbashir@bstmht.nhs.uk

doi: $10.1192 / p b .32 .2 .73 c$

\section{Can we harmonise forensic psychiatry across Europe?}

In their article Gordon \& Lindqvist (Psychiatric Bulletin, November 2007, 31, 421-424) refer to harmonisation of forensic psychiatry in Europe. We agree with the authors that, although laudable in principle, such undertaking is difficult, if not impossible, to achieve. However, it is possible to share experiences and learn from each other. One example of cooperation in forensic services between European countries is the development of the Dangerous and Severe Personality Disorder Programme (DSPD) in England, which was initially inspired by the Dutch Terbeschikkingstelling (TBS) system

Under TBS, the Dutch Criminal Code allows the detention of high-risk offenders with mental disorder. TBS has two components - a prison sentence followed by treatment in designated forensic units (van Marle, 2002). The duration of the sentence depends on the nature of the crime committed and the level of culpability.

Although it seemed prudent to adapt the TBS model, which had been tested over time, the final DSPD proposal came out fundamentally different. TBS order is issued and terminated by the courts, whereas in DSPD, offenders are detained under the provisions of the Mental Health Act 1983. This is despite earlier calls to develop a new strategy for high-risk offenders led by the judiciary, with psychiatrists' support (Coid \& Maden, 2003). The result has been criticism that psychiatry is being used for exercising social control. In our opinion such a composite arrangement meets neither the Dutch rehabilitative approach nor the public protection agenda.

COID, J. \& MADEN, T. (2003) Should psychiatrists protect the public? A new risk reduction strategy, supporting criminal justice, could be effective. BMI, 326, 406-407

VAN MARLE, H. J. C. (2002) The Dutch Entrustment Act (TSB): Its principles and innovations. International Journal of Forensic Mental Health, 1, 8-92.

*Najat Khalifa Clinical Lecturer in Forensic Psychiatry, The University of Nottingham, Duncan Macmillan house, Porchester Road, Nottingham NG3 6AA, email: najat.khalifa@nottingham.ac.uk, Mark H. Taylor Acting Consultant Forensic Psychiatrist, East Midlands Centre for Forensic Mental Health, Leicester

doi: $10.1192 / p b .32 .2 .74$

We read with great interest and appreciation the article 'Forensic psychiatry in Europe' by Gordon \& Lindqvist (Psychiatric Bulletin, November 2007, 31, 421-424).

The wide variety of forensic psychiatric practices in the 45 member states of the Council of Europe is not unlike what exists in the 50 states of the USA, each with its own criminal code and set of laws that frequently require the involvement of forensic psychiatrists. Indeed, the article could have been titled 'Forensic psychiatry in Europe and America.'

in the section on ethics in forensic psychiatry the authors call attention to reports of differences in the canons of ethics pertaining to US and British forensic psychiatrists. The fact is that one or two prominent US forensic psychiatrists visiting the UK have misinformed our British colleagues that forensic psychiatrists in the USA follow principles of ethics that are different from the code of medical ethics applicable to psychiatrists everywhere. We feel it is important for our British colleagues to know that the vast majority of US forensic psychiatrists do not subscribe to the notion that the so-called 'forensicist' operates outside the medical framework and does not act as a physician. Forensic psychiatrists throughout the USA would agree with Drs Gordon and Lindqvist that the knowledge and expertise on which the psychiatrist bases his or her work 'is that of medicine and psychiatry and the ethical framework is that grounded within [his or her] profession.'

In rejecting the overtures by 'forensicists' that a special code of ethics for them be adopted, the Ethics Committee of the American Psychiatric Association has declared that 'psychiatrists are physicians, and physicians are physicians at all times.'

*Abraham L. Halpern Professor Emeritus of Psychiatry, NewYork Medical College, 720 the Parkway, Mamaroneck, New York 10543-4299, USA, email: ahalpernmd@verizon.net, John H. Halpern Assistant Professor of Psychiatry, McLean Hospital, Biological Psychiatry Laboratory, Harvard Medical School, Belmont, Massachusetts

doi: 10.1192/pb.32.2.74a

\section{Mental health training for homelessness agencies}

We are encouraged to see that at least one trainee has pursued an active interest in homelessness/shelter populations (Psychiatric Bulletin, September 2007, 31, 326-329). However, we would like to throw further light on one of the author's conclusions. Stating that training is needed for shelter staff implies that there is little or no training available. In fact, a programme of training for voluntary sector organisations involved in homelessness was set up in London about 12 years ago. The Homelessness Training Unit is based in the Short Term Assessment and Rehabilitation Team (START, a mental health outreach team for homeless people) in Southwark but supplies modules of training to agencies all over London. CRISIS permanent staff receive training from the Unit team every year, although owing to the sheer number of volunteers (several thousand every year) it is only possible to train a tiny fraction of them. However, working with CRISIS is only a small part of what the Unit does.

In 2006 we ran 72 training courses for trainees from a total of 70 different organisations, double the number that were run 3 years ago. The courses ranged from general (Understanding and Recognising Mental Health Problems) to particular (Working with Schizophrenia). Agencies ranged from large, such as St Mungo's, to small, such as Romford YMCA. Many of the courses were bespoke, in-house training sessions developed with the client organisations. The feedback for these training modules has been consistently excellent.

One of the limiting factors in training CRISIS volunteers is the lack of time and their large numbers. However, most homeless people who attend a CRISIS shelter will be in touch for the rest of the year with one of the other organisations we offer training to, whether it be a hostel, a day centre or a street outreach team. It may well prove more costeffective to focus on those working permanently with homeless people as their daily experience is likely to 'cement' what they have learnt in their training.

We have been able to offer these courses free to cash-strapped voluntary agencies because of access to central funding. However, this central budget is being devolved to individual boroughs and it is uncertain how many of them, with their own cost pressures and local strategies, will wish to retain this funding.

PhilipTimms Consultant Psychiatrist, South London and MaudsleyTrust, email: philip.timms@ slam.nhs.uk， Steve Gardner Training Manager, START Team

doi: $10.1192 / p b .32 .2 .74 b$ 